\title{
O papel das atribuiçóes na constituição da hierarquia kadiwéu: uma análise das distinções eyiguayegui
}

GABRIELA DE CARVALHO FREIRE

UNIVERSIDADE DE SÃO PAULO (USP), SÃO PAULO/SP, BRASIL

HTTPS://ORCID.ORG/OOOO-OOOI-8IIO-85I2

\section{Nobres fajutos entregues ao ócio: a visão dos agentes coloniais sobre os senhores eyiguayegui}

[...] os mbayá têm sempre uma multidão de guanás que os servem como escravos voluntária e gratuitamente, que cultivam a terra para eles e lhes prestam outros serviços. Além destes escravos ou domésticos os mbayás encontram outros muitos nas crianças e mulheres que tomam na guerra e que não são somente índios, mas também espanhóis, de maneira que o mbayá mais pobre tem três ou quatro escravos. Estes vão pegar lenha, cozinham, levantam as tendas ou cabanas, cuidam da alimentação dos cavalos e de prepará-los para a montaria, e também cultivam as terras, o que é bem pouca coisa. Os mbayás não se reservam mais do que a caça, a pesca e a guerra; de maneira que me aconteceu de presentear um mbayá que não quis receber o regalo, ordenando a um de seus escravos recebê-lo: tão vãos e preguiçosos são (Azara, 1809:63, tradução minha). 
Ao mesmo tempo em que eram reconhecidos como os "índios cavaleiros", opositores ferozes da colonização espanhola e portuguesa nas regiões do Chaco $^{1}$ e de Cuiabá, os índios Eyiguayegui ${ }^{2}$ - referidos por Félix de Azara, comissário e comandante das fronteiras espanholas no Paraguai de 1781 a 1801, como "mbayá" e conhecidos atualmente como Kadiwéu ou Caduveo - eram também recorrentemente representados nas fontes históricas como "vãos e preguiçosos", inimigos "da agricultura e do trabalho" (Almeida Serra, 1850: 370). Assim, sua imagem de incansáveis guerreiros convivia com a de nobres fajutos e entregues ao ócio. Segundo os documentos, eles podiam passar dias inteiros sem comer, se isso os pusesse a salvo da vergonha que sentiriam ao cultivar a terra. De acordo com Almeida Serra (1850: 204-5), comandante da Coroa Portuguesa que acompanhou a construção do Forte de Nova Coimbra na metade do século XVI, a "altivez e negação ao trabalho" dos capitães eyiguayegui os teria feito "desprezar as fadigas da agricultura" e negar qualquer tipo de atividade que pudesse colocar em risco sua nobreza. Sua solução para esse impasse parecia ser simples: saqueavam dos outros, povos agricultores, o sustento de que precisavam para se manterem vivos. Os primeiros relatos escritos por exploradores como Cabeza de Vaca $\left([1555]^{3}\right)$ e Schmidel ([1602]), exploradores que protegeram o Forte Assunção nos séculos XVI e XVII, narram os diversos ataques empreendidos por indígenas eyiguayegui às roças guarani, além das trocas amigáveis que aconteciam entre esses povos. Em todas essas descrições, os índios cavaleiros saíam carregados de provisões: milhos, batatas, feijões, abóboras...

Já no final do século XIX, quando os portugueses tentavam aproximar-se dos indígenas e valer-se de sua mão de obra, uma oferta foi apresentada aos Eyiguayegui: poderiam eles "plantar milho, feijão e criarem porcos" para os militares residentes no Forte Coimbra, sendo-lhes garantido como retribuição o pagamento em forma de "ferramentas, panos brancos, rapaduras, aguardente" etc. Depois de discutir longamente a proposta com o conselho de chefes, o capitão dos Eyiguayegui veio dizer aos portugueses que "tudo estava muito bem e que elles assim o queriam", completando logo: quantos "escravos" haviam de mandar para fazer aquelas roças? Porque, segundo afirmava, eles não eram cativos. Da mesma forma agiram quando lhes trouxeram madeiras para a construção de novas cabanas: disseram "que as madeiras para elles eram muito duras, e molestavam os hombros, que todos as queriam, mas que lh'as fossem fazer os portugueses" (Almeida Serra, 1850: 349). Cultivar a terra e carregar madeiras pesadas,

1 O Chaco tem como limites naturais os rios Paraná e Paraguai a leste, as cordilheiras andinas a oeste, o planalto mato-grossense a norte e a bacia do rio Salado ao sul (Tola, 2013:12). Os estudos do Chaco convencionaram dividi-lo, de acordo com seus níveis pluviométricos, em três sub-regiões: Chaco úmido, em sua porção oriental, Chaco central e Chaco seco, a leste. Pode-se também subdividir a região chaquenha em Chaco boreal, ao norte do rio Pilcomayo, Chaco central, entre os rios Pilcomayo e Bermejo e o Chaco austral, a sul do Bermejo (Tola, 2013:12). Existem mais de vinte povos indígenas na região chaquenha, divididos em seis grupos linguísticos principais: "Mataco-maká (Wichí-Mataco, Chorote, Nivaclé-Chulupí, Maká), Guaycurú (Toba, Toba-Pilagá, Pilagá, Mocoví, Mbayá-Caduveo), LuleVilela (Chunupí), Lengua-Maskoi (Lengua, Sanapaná, Angaité, Enenlhet), Zamuco (Chamacoco-Ishir, Ayoreo) e Tupí-Guaraní (Ava-Chiriguano, Chané, Tapiete, Isoseño-Guaraní, and Guaraní Occidental)" (Combès et al 2009: 69).

2 Lê-se "edjiguadjegui”. Os Eyiguayegui, mais conhecidos como Kadiwéu, são os únicos descendentes atuais dos Mbayá, que eram falantes da língua Guaicuru e habitavam a margem ocidental do Rio Paraguai, no Chaco paraguaio. Segundo o missionário Sánchez-Labrador ([177-1776], v. II:5), esses coletivos, reconhecidos na maioria das vezes como Mbayá, Guaicurú ou Mbayá-Guaicurú se autodenominavam Eyiguayegui, que significa, na língua Mbayá, "oriundos do local em que abunda a palma Eyiguá". Respeitando a autodenominação destes grupos, usarei o etnônimo Eyiguayegui para me referir aos ancestrais dos atuais Kadiwéu do Mato Grosso do Sul, respeitando, porém, os etnônimos utilizados pelas fontes em caso de citação.

3 Considerando a data da primeira publicação das obras aqui analisadas uma informação de grande importância para o desenvolvimento do argumento, optei por informar, nas citações, apenas esta data, entre colchetes. A edição consultada e citada é informada nas fontes e referências bibliográficas. No caso dos relatórios militares publicados na Revista do Instituto Histórico e Geográfico Brasileiro, cita-se apenas a data de publicação do volume da revista. 
pelo que se depreende das descrições, não era tarefa para boa parte dos Eyiguayegui. Aliás, o "desprezo" desses indígenas pela agricultura foi um dos principais motivos alegados para o fracasso das sucessivas tentativas de aldeamento empreendidas pelos jesuítas no século XVIII: os missionários não tinham o que comer porque os indígenas se recusavam a trabalhar nas roças (Susnik, 1972:79; Herberts, 2011:22). De acordo com eles, essa era uma tarefa para seus servos e escravos e - por que não? - para os próprios missionários.

Como conjugar o gênio marcial e aristocrático eyiguayegui à "preguiça” desmoralizante que muitas vezes lhes era atribuída? De que maneira os autores das narrativas coloniais conectavam essas características, antagônicas à primeira vista? Em que medida essa "preguiça" descrita pelos documentos coloniais define a nobreza eyiguayegui e a suposta hierarquia chaquenha? E como as atividades realizadas pelas pessoas contribuía na construção das distinções que operavam nas aldeias eyiguayegui ? $\mathrm{O}$ presente artigo se debruça sobre questões como essas, procurando interpretar, à luz de contribuição de etnografias relativamente recentes sobre os Kadiwéu, as informações sobre os "índios cavaleiros" trazidos pelos escritos de agentes coloniais, sejam eles missionários ou funcionários da burocracia estatal.

De saída, é necessário atentar para o fato de que as fontes analisadas não configuram a totalidade da documentação colonial sobre os Eyiguayegui, e não foi meu objetivo explorar esse universo de relatórios, cartas e livros do período que vai do século XVI ao XX. Como a principal intenção da investigação foi a de colocar em diálogo obras históricas e contemporâneas que fundamentam as análises da política eyiguayegui e kadiwéu, acabei por focar nos documentos históricos geralmente citados como base para a caracterização desses povos como "hierárquicos" e na apreensão das diferenças que os compõem ${ }^{4}$.

\section{Trabalho e servidão}

A pesquisa que fundamenta o artigo teve como indagação inicial o porquê da caracterização dos Eyiguayegui, na literatura histórica e antropológica, como "hierárquica" ou, nas palavras de Pierre Clastres (2003:46), organizada por uma "clara estratificação em castas". Como demonstrado, em grande parte dos relatos, eles são representados como índios "soberbos" que se diziam "nobres" e "senhores" dos indígenas que haviam sido capturados na guerra - os nibotagi, denominados pelos europeus de "escravos" - e das populações agrícolas com quem mantinham relações próximas - os niyolola, ou "servos", que podiam ser de diversos grupos, como os Guaná e os Chamacoco, dependendo do momento histórico.

Ao me dedicar à análise cuidadosa de alguns dos relatos históricos e à tentativa de percorrer os caminhos que os levaram a denominar relações indígenas por meio de noções como "escravidão", "servidão", "nobreza" e "aristocracia", acabei por encontrar descrições de relações complexas, que podem parecer contraditórias à primeira vista. Apesar de afirmarem uma estratificação entre as "camadas" dos cativos/servos e dos capitães, as crônicas admitiam muitas vezes que sua linguagem era limitada e não

4 Uma apresentação mais detalhada das obras analisadas foi realizada em minha dissertação (Freire, 2018), onde também aprofundei a discussão sobre a metodologia da leitura de fontes históricas à luz de reflexões antropológicas contemporâneas. 
podia exprimir a complexidade do que estavam tentando descrever: essa "hierarquia" era repleta de elementos considerados contrários a ela, como a ascensão de "escravos" à aristocracia, descrita por fontes como Sánchez-Labrador ([1770-1776]) e Boggiani ([1895]) e comentada e analisada por autores como Claude Lévi-Strauss (1996) e Rengger (2010)5 , e o "carinho" dedicado pelos "senhores" a seus “criados", muito bem descrita pela expressão "dulce esclavitud”, de Félix Azara ([1809]). As questões levantadas pela leitura das fontes, assim, foram: por que, mesmo que haja relações de proximidade entre "senhores" e "escravos" e mesmo que "escravos" possam se tornar chefes, a caracterização das relações entre os Eyiguayegui sempre foi descrita por meio do conceito de hierarquia? E a partir de que evidências são definidas as condições de "nobres", "escravos" e "servos"?

Levada por essas perguntas, a leitura paralela dos documentos históricos e da produção antropológica posterior nos faz perceber que, em grande parte dos antigos relatos, a nobreza e a "preguiça" são tomadas como consequência uma da outra, sendo a "indolência" dos Eyiguayegui uma das facetas (e indícios evidentes) de seu caráter qualificado como aristocrático. Como se verá a seguir, toda a construção da ideia de aristocracia eyiguayegui pela documentação colonial tem como base o fato de tais "senhores" não trabalharem. A noção de "trabalho" mobilizada nas fontes, por sua vez, parece estar ligada a atividades "domésticas" e agrícolas, aquelas evitadas pelos "capitães, que se reservavam, como já escrevia Azara, apenas à caça, a pesca e a guerra. Veremos que o "horror" dos Eyiguayegui pelo "trabalho", que consideravam "próprio de escravos", era diretamente relacionado pelos autores coloniais à sua “innata soberba” (Almeida Serra, 1850: 348).

Fica evidente, portanto, que a literatura sobre os Eyiguayegui efetua uma ligação entre os conceitos de "trabalho" e de "servidão". De fato, parece ser no encontro entre essas duas noções que a "estratificação social" eyiguayegui começa a tomar forma: é perceptível a associação direta entre (um determinado tipo de) trabalho e servidão efetuada não apenas nos documentos históricos, mas também em análises antropológicas.

Essa conexão automática entre as duas noções, por sua vez, parece ter origem na forma como foram vistas as diferentes atribuições eyiguayegui. Em primeiro lugar, os autores das fontes já distinguiam o tipo de tarefas realizadas, ou seja, o que "nobres" e "escravos" faziam de acordo com seus próprios termos. De saída, algumas atribuições (categorizadas como "trabalho") eram entendidas como inferiores às outras. Em segundo lugar, há uma preocupação com a maneira pela qual se realizavam as tarefas, ou seja, como os "escravos" e "servos" executavam algumas atividades. De acordo com as fontes e alguns antropólogos, a particularidade dos nibotagi e niyolola era que eles não apenas executavam certas tarefas, mas as faziam a serviço de seus "senhores", servindo-os em qualquer momento. Sugiro que na base dessa visão estão certas definições de trabalho e servidão que fazem com que atividades diferentes - mas não necessariamente percebidas pelos indígenas como desiguais em valor - sejam vistas como base de uma hierarquia.

Nesse sentido, a noção de trabalho parece estar, desde sua origem, vinculada à ideia de poder que acaba sendo transplantada para nossas análises. Minha sugestão, portanto, é a de refinar nosso vocabulário quando nos referimos às tarefas realizadas pelos indígenas. No lugar de trabalho, utilizo daqui em 
diante o termo atribuição quando estiver me referindo aos afazeres das pessoas. O termo é inspirado na etnografia dos Kalapalo feita por Guerreiro Jr. (2012), e chama atenção para o fato de que, ainda que algumas tarefas sejam feitas por uma pessoa para outra, isso não necessariamente significa a existência de um sistema hierárquico por trás dessas ações. Ou seja, assim como as relações kalapalo que são mediadas por atribuições, também as relações eyiguayegui não trazem necessariamente consigo uma divisão hierárquica, não definindo uma posição fixa nem para o agente da ação nem para aquele que a demanda. Sugiro que os dados eyiguayegui sejam lidos nessa chave: não podemos negar que alguns fazem determinados serviços para outros, mas podemos duvidar do sistema hierárquico que se supõe por trás desses atos.

Nesse artigo, procuro me deter mais no primeiro aspecto da relação entre algumas atribuições e a servidão tal como operada nas fontes, ou seja, ao fato de que algumas tarefas são entendidas como essencialmente inferiores a outras. É importante destacar que, nessa análise crítica, não pretendo fazer uma leitura que valorize mais os aspectos "hierárquicos" nem os aspectos "igualitários" das relações eyiguayegui. Ao contrário, considero, como diversas outras reflexões acerca das políticas ameríndias, que podem existir movimentos centrífugos e centrípetos (Clastres, 2004), a depender de diversos fatores. Nesse sentido, procuro analisar as descrições das fontes históricas fundamentada nesse "perpétuo desequilíbrio" que Lévi-Strauss afirma ser próprio às filosofias políticas indígenas, e entender os dados trazidos por elas de uma maneira menos rígida e mais fiel à "inconstância” que caracterizaria, segundo Viveiros de Castro (2002), as relações e os corpos ameríndios.

\section{"Mais uma carga do que uma honra": as atribuições do posto de chefia}

Uma das figuras mais complexas descritas pela literatura é a dos chefes eyiguayegui. À primeira vista, o que salta aos olhos são termos que indicam duras restrições matrimoniais, que parecem afirmar que esses "nobres" não se casariam com seus criados. Porém, ao mesmo tempo, as descrições analisadas enfatizam o contrário: grande parte das crônicas aponta para o movimento realizado pelo/os nobres de procurar cônjuges fora do âmbito local e de criar crianças cativas trazidas do exterior das tolderías. A nobreza eyiguayegui parecia se constituir, portanto, não por uma concepção de "pureza" que enclausuraria os capitães em uma sociedade em que o casamento é impossível - como sugere Lévi-Strauss em Tristes Trópicos -, mas no seu exato oposto, ou seja, na procura mesma pelo Outro e pelo exterior, e pelas relações matrimoniais que se espraiariam Chaco adentro.

Ainda assim, existia - e ainda existe entre os Kadiwéu, segundo etnografias contemporâneas como as de Duran (2016), José da Silva (2004), Padilha (1996), Pechincha (1994), Ribeiro (1980a, 1980b), Siqueira Jr (1993) e Lecznieski (2005) - uma valorização da hereditariedade. Os relatos descrevem, por exemplo, uma grande festa que acontecia sempre que o filho de um dos capitães nascia, o que acabava por construir seu prestígio desde recém-nascido. Mas, na mesma festa, era também escolhida uma criança filha de nibotagis que iria gozar, junto com o filho do capitão, do título de chefe. Nesse sentido, ao mesmo tempo em que havia uma dose de herança na chefia eyiguayegui, havia tam- 
bém a construção gradual das características de um grande chefe, o que em algumas vezes prescindia do "sangue" nobre. Havia também a construção de outras lideranças, que não vinham dessas linhagens nobres, o que não é raro no Chaco. Em consonância com as descrições sobre a "hierarquia" eyiguayegui, Diego Villar (2013), por exemplo, argumenta que há, na hereditariedade dos Chané do Chaco boliviano, matizes que a tornam passível de diversas maneiras de manipulação.

Segundo as fontes, existiam dois tipos de chefes eyiguayegui: o primeiro tipo era composto pelos que "goza[va]m daquela regalia" por conta de seu sangue e, o segundo, por aqueles que a recebiam em outras ocasiões, como na festa do capitãozinho. Todos se chamavam niniotagi. Ao capitão grande - o herdeiro da capitania - dava-se o nome de niniotageleudi, uma junção de iniwtagodi (meu senhor) e eleudi (grande). Este último adjetivo, eleudi ou elegi, era sua forma de denominação mais cotidiana. O capitão pequeno chamava-se niniotagilionigi, onde niniotagi pode ser traduzido como "capitão" ou "senhor" e ionigi como "filho". Os capitães pequenos eram também denominados inionigi-iguaga, ou "semelhante a capitão"6.

O título de elegi era aplicável não apenas aos capitães grandes, mas também a suas mulheres e filhas. Ainda que os documentos históricos afirmem muitas vezes que a nobreza era transmitida via linha paterna, eles trazem dados também de elegi filhos apenas de uma "senhora" e de pai "comum" ou mesmo nibotagi. O título de niniotageleudi podia, portanto, ser transmitido tanto por linha paterna quanto materna ${ }^{7}$, e não havia uma propensão maior para o lado masculino, como em outros contextos - refiro-me aqui ao contexto alto-xinguano e, mais especificamente, o Kalapalo, tal como descrito por Guerreiro Jr. (2012). Tampouco há dados que demonstrem uma menor potência da nobreza quando apenas um dos pais era nobre: segundo as fontes, capitães grandes podiam ser filhos tanto de pai e mãe nobres como apenas de um pai ou mãe de linhagem aristocrática.

Os elegi - também denominados por Sánchez-Labrador " "caciques" - eram os chefes das tolderias, apresentando características muito parecidas com aquelas do titular chief (ou "chefe titular") de Lowie (1948: 273-6). A generosidade, a boa oratória e a habilidade de agregar um grupo de pessoas e mantê-lo em certa harmonia eram certamente requisitos de um bom elegi. Aliado a esses aspectos, a posição de chefia parecia ser também esvaziada de poder, como no modelo proposto por Pierre Clastres (2003) inspirado nas observações de Lowie. A descrição de Radin (1946), baseada no testemunho do jesuíta Martín Dobrizhoffer ([1784]) sobre o posto de “cacique” entre os povos de língua Guaicurú, é exemplar nesse sentido. Segundo o antropólogo, ser capitão entre aqueles índios era

mais uma carga do que uma honra e com frequência este posto traz[ia] mais perigo do que proveito. Pois não reverencia[va $] \mathrm{m}$ a seu cacique como um mestre nem lhe paga[va] $\mathrm{m}$ tributo ou ajuda como é costume em outras nações. Não o invest[ia]m com a autoridade de um juiz, um árbitro ou um vingador... Se repreend[ia] alguém por suas transgressões, com uma só palavra dura

6 A denominação dos capitães é informada por Sánchez-Labrador ([1770-1776], v. II: 19), e a tradução dos nomes é trazida por Mônica Pechincha (1994: 34).

7 Afirmação feita também por Cabeza de Vaca ([1555]:159).

8 Sánchez-Labrador foi um jesuíta ligado à Companhia de Jesus que fundou entre os Mbayá do norte a missão Nossa Senhora de Belém em agosto de 1760. 
ser[ia] castigado na seguinte bebedeira, para beber com os punhos dos selvagens embriagados, e o encheriam publicamente de insultos, como amigo dos espanhóis e como alguém que ama mais a tranquilidade que a seu povo (Radin, 1946: 188, tradução minha).

Os "proveitos" do posto de chefia, nesse sentido, eram poucos. Na verdade, os elegi pareciam estar sempre tentando atingir o ideal de um bom chefe, que correspondesse às expectativas do grupo. Entre as "cargas" que não apenas os elegi, mas os niniotagi em geral tinham que carregar para continuarem a ser "nobres", estava a função de anfitrião das festas. A seguinte descrição de Boggiani ([1895]:188) esclarece esse ponto:

Por quanto tenho observado até aqui parece que os Caduveo gostam de fazer exibição de grandiosidade e generosidade, mal se achem em condições de fazê-lo. Não gostam de embriagar-se egoisticamente sozinhos; precisam para tanto de boa companhia; parece-lhes necessário que todos saibam que tal indivíduo está em condições de oferecer aos amigos o prazer imenso de tomar uma solene bebedeira, que se cante, se dance alegremente, se faça rumor; que os garrafôes de aguardente de que dispõe sejam esvaziados com toda cerimônia e com grande pompa; que a memória do festim dure longamente e o anfitrião chegue a superar, com a sua generosidade e o esplendor da sua festa, as festas anteriores.

O esbanjamento descrito por Boggiani não era simples mostra de fartura dos anfitriões, ou apenas a procura pela companhia nas bebedeiras, como interpreta o comerciante. De acordo com a afirmação do próprio italiano, os ofertantes das cerimônias tinham a preocupação de "superar, com a sua generosidade e o esplendor de suas festas, as festas anteriores", ou seja, as festas dos outros anfitrióes - o que evoca diretamente as competições em forma de potlatch entre os "chefes" da Columbia Britânica. Os niniotagi (e também os aspirantes a niniotagi) estavam sob constante pressão de afirmar sua nobreza sobre a dos outros. Essa confirmação, por sua vez, se dava por meio de exibições de "grandiosidade e generosidade". "Embriagar-se egoisticamente sozinho", nesse caso, seria visto como uma grande afronta a seu grupo e como sinal de mesquinhez: um dos grandes xingamentos eyiguayegui era exatamente a acusação de sovinice, acami aquilegi - "você é um covarde, miserável, mesquinho e nada liberal", segundo Sánchez-Labrador ([1770-1776], v. I: 252, tradução minha). A nobreza dos niniotagi é indissociável, portanto, de sua generosidade e capacidade de distribuição: assim que voltavam de suas incursões a outras aldeias, os chefes davam aos outros habitantes das tolderías tudo o que haviam roubado ou recebido de presente. Sendo o momento mais propício para a mostra de generosidade, as festas são centrais na construção da nobreza e dos estatutos eyiguayegui.

Nesse sentido, e como afirma Perrone-Moisés (2015: 53), a festa ameríndia não deve ser vista como acessória à política; ela efetivamente é (o que chamaríamos de) política. Merekuku Apalay, interlocutor da etnóloga, ao comentar que "dono de festa é como chefe", resumia a conexão que, segundo a autora, é evidente: como um anfitrião, o chefe deve ser generoso, bom orador, promotor da concórdia; e os chefes ameríndios têm de modo geral a obrigação de oferecer festas, de saber cantar e dançar e de ser "detentor" de objetos de festa, como afirmava Boggiani sobre as festas eyiguayegui; em suma, têm 
que saber como oferecer momentos de alegria (Perrone-Moisés, 2015: 5). Por isso, Boggiani descrevia anfitriões preocupados em fazer com "que todos saibam que tal indivíduo está em condições de oferecer aos amigos o prazer imenso de tomar uma solene bebedeira, que se cante, se dance alegremente".

$\mathrm{E}$ as atribuições dos niniotagi não paravam por aí. A última passagem do excerto de Radin aquela que coloca em contradição "amar a tranquilidade" e, ao mesmo tempo, "seu povo" - remete a outra característica dos chefes ameríndios tal como descritos na tese clastreana, também presente no Chaco: sua ferocidade e predisposição para a guerra. Assim, ao mesmo tempo em que deve ser generoso e bom anfitrião, agregando em volta de si o maior número de pessoas possível, o chefe ameríndio - e eyiguayegui, como as fontes parecem mostrar - devia também ser feroz, lutando contra uma unificação que levaria à centralização (Clastres, 2004). E esse ímpeto ao exterior não devia se mostrar apenas na guerra: como afirmei acima, era importantíssimo que os elegi procurassem se casar com pessoas de outras localidades, trazendo-as para dentro de suas tolderías. Uma das principais atribuições da nobreza eyiguayegui, nesse sentido, era a de se relacionar com o exterior e trazê-lo, já controlado, para as relações domésticas.

É importante notar que essa nobreza não era composta apenas por chefes: o título de chefe não se estendia necessariamente à nobreza dos niniotagilionigi - capitães pequenos. Ainda assim, os niniotagilionigi formavam, em conjunto com os elegi, um grupo de pessoas que tinha na festa e na guerra suas maiores atribuições. No mais, outro ponto a ser ressaltado é o fato de que a nobreza dos capitães pequenos era apenas vitalícia, não sendo transmissível para as gerações futuras, como no caso dos capitães grandes. Eles podiam adquiri-la nas festas de criação dos capitães e também quando demonstravam certas aptidões para o cargo, como a capacidade de ser um bom anfitrião e a vocação para a guerra. É importante notar, assim, que os nibotagi que apresentassem as qualidades esperadas de um bom chefe podiam muito bem virar capitães de uma toldería inteira, enquanto pessoas que recebiam, por nascimento, o "título de nobreza" e não se esmerassem em desenvolver as aptidões do cargo, ou cujos pais não investissem na festa de criação do capitão e outras festas iniciáticas, não eram tidas como chefes. A criação gradual do chefe parece ser, nesse sentido, muito mais importante que a hereditariedade da posição. Ainda assim, opto por continuar a utilizar aqui o termo "nobreza", por haver algumas similaridades com a noção europeia: ambas parecem se referir a um porte específico, comedimento e boa educação. Não deixo de notar, porém, que existem grandes diferenças entre a "nobreza" eyiguayegui e a dos europeus: a hereditariedade e a "pureza" que parecem ser requisitos no último caso, por exemplo, não são nem de longe o ideal da aristocracia chaquenha.

De onde vêm, então, os motivos para a literatura sobre os Eyiguayegui efetuarem uma separação tão marcada entre os nobres e os nibotagi e o niyolola? Como demonstrado, as relações entabuladas dentro das tolderías são lidas pelas fontes por meio da oposição niniotagi/nibotagi, e praticamente todas as descrições de um nobre presentes nos documentos históricos são feitas em oposição à de um “escravo" ou "servo". Não há, pois, nobreza sem que haja “escravidão"/"servidão", e a matéria-prima dessa distinção parece ser os tipos de tarefas realizadas pelos niyolola, nibotagi e niniotagi, descritas nas fontes como anteriores a eles, definindo-os. Tendo apresentado preliminarmente as atribuições de um bom niniotagis apresento nas próximas páginas as tarefas dos nibotagi e niyolola. 


\title{
"Não podiam fugir porque tinham uma tarefa a fazer": atribuições do niyolola e nibotagi
}

\begin{abstract}
Nobres cavaleiros e nobres damas se divertiam nos torneios; estavam livres dos trabalhos subalternos graças a uma população instalada havia mais tempo, diferente pelo idioma e pela cultura, os Guaná. [...] Esses Guaná cultivam a terra e pagam um tributo em produtos agrícolas aos senhores mbaiá em troca de sua proteção, para se preservarem da pilhagem e das depredações feitas pelos bandos de cavaleiros armados, entende-se (Lévi-Strauss, 1996: 191).
\end{abstract}

A descrição de Lévi-Strauss, feita com base na leitura dos documentos históricos, versa sobre a "relação de servidão" entre os Eyiguayegui e os Guaná. Além desse pacto hipotético que teria fundado a relação entre as duas populações, há outra particularidade dos "servos", como se depreende da leitura do excerto e das fontes: sua especialização nas tarefas da terra, que acabaria por deixar "livres dos trabalhos subalternos" os "nobres cavaleiros", ocupados com a "diversão" proveniente das festas e dos jogos (os "torneios"). Ainda que as fontes descrevam, muitas vezes, os niyolola "servindo" a seus senhores em diversas atividades, sua atenção recai sempre na vocação para a agricultura: "os Guaná” cultivavam "a terra em roças trabalhosas, mas grande parte de seus esforços" serviam de "alimento para seus amos vagabundos", conta Sánchez-Labrador ([1770-1776], v. I:305, tradução minha). Seu trabalho da terra seria trocado, por sua vez, pela vocação para a guerra de seus "senhores", como afirma Lévi-Strauss. O "contrato de vassalagem" entre essas duas populações criaria uma relação entre uma sociedade-para-a-guerra e uma sociedade-para-a-agricultura, fazendo-as trocar suas especializações entre si.

De forma parecida, os nibotagi, denominados pelas fontes "escravos", também eram reconhecidos por suas atividades. Segundo os autores, eles eram indispensáveis ao cotidiano dos toldos, pois todos os serviços do seu dia a dia estavam ao seu encargo. Fazia parte de suas atribuições "abastecer os toldos dos senhores de água, lenha e coisas semelhantes" (Sánchez-Labrador [1770-1776, v. I]:133, tradução minha), além de cozinhar, buscar palmas de eyiguá, construir e limpar os toldos, cuidar dos cavalos e, às vezes, caçar e pescar (Métraux, 1946:308).

É importante notar que, embora existam diversas descrições dos niniotagi fazendo todos esses tipos de tarefas, apenas nibotagi e niyolola são por elas definidos. Boggiani ([1895]:133), por exemplo, afirma que aos escravos competia "os trabalhos grosseiros de serviço e o lavrar a terra", serviços condizentes com sua condição "selvagem”. De maneira parecida, o antropólogo Santos-Granero, no livro Vital Enemies (2009: 95), em que se debruça sobre casos de "servidão" nas terras baixas sul-americanas, entre eles o dos Eyiguayegui, também relaciona os cativos de guerra às "tarefas mais árduas", definindo-os como "serviçais domésticos". Susnik (1972: 89), por sua vez, afirma que aos escravos cabia todo o trabalho e conta da ocasião em que os Eyiguayegui se comprometeram a ajudar os portugueses a construir o Forte Bourbon, mas se recusaram a fazer o serviço, deixando-o para seus "escravos", pois o consideravam um "trabalho pesado".

É perceptível que a definição de "escravos" e "servos" como pessoas que se ocupam com certas tarefas está diretamente relacionada à definição de outras pessoas - os nobres - que não se ocupam 
com essas atividades. Lecznieski (2005:225), por exemplo, escreve que muitos Kadiwéu não executam "tarefas consideradas árduas e menores", preferindo contratar outras pessoas que possam "lavar roupa no riacho, 'levantar uma casa' ou buscar matéria-prima para 'levantar cerâmica'”. Ela conta que, no início de sua estadia entre os Kadiwéu, seus nobres anfitrióes - ela estava hospedada na casa do capitão Paulínio e sua esposa Durvalina, descendentes da família Silva, uma das famílias nobres kadiwéu - insistiam para que ela não fizesse nenhum "trabalho pesado", "na 'torreira do sol'” pois, segundo eles, esse não era "serviço para brancos" e eles tinham "outras pessoas para fazer esse tipo de serviço" (Lecznieski, 2005:13). A antropóloga narra que, mesmo com essa inicial reprovação, ela e seu marido continuaram a fazer atividades consideradas "menores", fato que logo passou a ser aceito pelos Kadiwéu. Tanto que, aos poucos, eles começaram a ser requisitados para efetuar aquele tipo de tarefa para seus anfitriões e familiares. “[S]e nos recusávamos a ser nobres, então que fôssemos cativos!", escreve Lecznieski (2005:201).

A autora conta que atualmente os Kadiwéu contratam, de tempos em tempos, alguém para cultivar as roças. Segundo a antropóloga, eles manifestam abertamente um "desagrado em relação às atividades agrícolas, explicando que a contratação de empregados se deve sobretudo ao fato de se tratar de um trabalho árduo, que maltrata a pessoa, obrigada a passar muito tempo 'com a cabeça rachando no sol'”. Nessas ocasiões, eles assumem a posição de "coordenadores do trabalho", assim como os antigos Eyiguayegui faziam com os Guaná - os “mutirões” de agricultores guaná são descritos em Freire (2018). Não é de se estranhar, portanto, que a maior parte dos agricultores da R.I. Kadiwéu sejam os Terena e Kinikinau, descendentes autodeclarados dessa população chaquenha. Segundo as etnografias atuais, os Terena e Kinikinau tendem a se concentrar em aldeias separadas da maioria dos nobres kadiwéu, como as aldeias Campina e São João. De acordo com Siqueira Jr. (1993:128), mesmo sendo "visivelmente mais pobres", seus moradores são reconhecidos por "suas qualidades de lavradores e suas capacidades de trabalho, uma vez que as maiores e melhores roças estão localizadas na Campina”. A vocação dos descendentes dos Guaná para a agricultura é também expressada por Martinho Silva (nobre kadiwéu) quando este conta sobre a época - meados nos anos 1940 - em que o SPI realocou algumas famílias Kinikinau e Terena para a RI Kadiwéu constituindo, na ocasião, a aldeia São João (José da Silva, 2011: 61).

Nas palavras de Martinho,

[e]sses Terenas, vem sendo aliado com os Kadiwéu, sempre vivendo subordinados, os Kinikinau subordinados aos Kadiwéu. Não podia fugir porque eles tinham uma tarefa a fazer [...]. Então eles, os patrícios9 disseram: - Então vocês ficam aqui [...], aqui é o canto da nossa área, aqui qualquer coisa, qualquer irregularidade que vocês vê, procuram nos localizar, nos avisar o que está acontecendo. Agora vocês têm obrigação, planta milho, arroz, feijão, tudo o que se dá aqui vocês planta, e nós vamos comercializar entre nós mesmos, lá pelo rio Paraguai, por aí, tudo o que nós conseguir nós entrega aqui, nós não temos como negociar [...] Nós vamos negociando isso aí, vocês ficam

9 É comum encontrar fala dos capitães e seus cativos referindo-se à parte dos nobres como patrícios, termo que geralmente se refere aos membros da nobreza da Roma antiga e àqueles que têm atitudes distintas, de aristocrata. O uso desses termos, assim como "nobre" e "cativo" indica a adoção de um vocabulário que lhes foi aplicado ao longo dos séculos por agentes coloniais e antropólogos, adoção esta que, ainda que tenha sido imposta, nunca foi efetuada de maneira impensada pelos Kadiwéu. 
como vigilante nosso, como ponto de segurança nosso. Aí toparam, onde existe o PI São João (Siqueira Jr, 1993:130).

Os Terena e Kinikinau foram levados à R.I. Kadiwéu por Horta Barbosa com a intenção declarada de povoar o território para que os ataques de fazendeiros diminuíssem. Segundo Martinho, a "obrigação" dos Terena e Kinikinau seria a de avisar caso houvesse alguma invasão, ficando como "vigilantes", "pontos de segurança”. O relato de Martinho nos faz ver, além disso, que essa relação de "trabalho" é um dos pilares de sustentação da relação niniotagi-nibotagi/niyolola. Os Terena teriam a obrigação moral de cumprir uma espécie de código de honra: "[n]ão podia[m] fugir porque eles tinham uma tarefa a fazer".

Podemos depreender, ainda do testemunho de Martinho, que há uma contrapartida às obrigações dos Terena e Kinikinau. Segundo ele, os agricultores tinham a tarefa de plantar, e os Kadiwéu, a de comercializar entre eles ou "lá pelo rio Paraguai" tudo o que conseguissem. Mais uma vez, esse acordo lembra muito aquele descrito pelos documentos históricos, em que os Eyiguayegui trocavam os produtos agrícolas guaná pelas manufaturas dos europeus. A vocação de "comerciantes" dos Eyiguayegui aparece também nas descrições coletadas por Susnik, quando esta afirma que os senhores deixavam seus "escravos" trabalharem no Forte Bourbon para ficarem livres "para fazerem alianças e trocas" com os portugueses (1972: 82).

\section{Preguiça ou vergonha? Diferentes olhares sobre a nobreza Eyiguayegui}

Além de se ocuparem com os "negócios", a festa e a guerra, os niniotagi realizavam muitas outras tarefas. Segundo a documentação colonial, os "capitães" - que pareciam não fazer outra coisa senão estar em guerras (Schmidel, [1602]:79) - ocupavam-se também com as expedições de caça, com a prataria, a confecção de lanças e flechas, a construção de canoas, a preparação dos couros de cervos, veados e gado (Sánchez-Labrador, [1770-1776], v. I:297) e a coleta de carandás, palmitos e mel (Rodrigues do Prado, 1795:33). Além disso, eram descritos como exímios veterinários, pois cuidavam sempre do gado, das ovelhas e dos cavalos. Estes últimos, aliás, eram centrais tanto nas expedições guerreiras quanto dentro das tolderías - de acordo com Sánchez-Labrador, os (nobres) donos dos cavalos conheciam "las enfermidades de sus caballos mejor que las suyas próprias", e lhes direcionavam o melhor dos cuidados, gastando muito de seu tempo com eles (Sánchez-Labrador [1770-1776], v. I:298). A relação dos "senhores" com seus cavalos era (e continua sendo) tão próxima que a antropóloga Branislava Susnik chegou a falar sobre a possibilidade de uma "crise étnica" eyiguayegui nos fins do século XVIII, quando os paraguaios tentaram colocar em prática um plano de "desequestrização" daqueles índios, visando a diminuir seu poder bélico: segundo Susnik (1972: 91), os aristocratas eyiguayegui não podiam se ver sem seus cavalos, correndo o risco de virarem "escravos" ou, em língua eyiguayegui, nibotagi.

A "preguiça" dos chefes eyiguayegui, nesse sentido, não se refere à falta absoluta de afazeres por parte dos "senhores". Na realidade, a acusação de que a aristocracia vivia em função da diversão parece 
se ancorar não na ausência de atividades, mas em sua não ocupação com certas atividades. Como afirmei acima, a definição dos nobres está diretamente ligada àquela dos escravos: segundo as descrições, o que um fazia o outro não fazia. O termo nibotagi é um exemplo disso. Mesmo que ele tenha sido muitas vezes traduzido por "escravo" ou "cativo", seu significado exato não é conhecido. A interpretação mais razoável parece ser a de Susnik (1972: 67), que define aqueles reconhecidos como nibotagi não por si, mas em relação àqueles que não se encaixam nessa categoria, de maneira parecida com a dupla niyolola-oquilidi. Segundo a antropóloga, o termo nibotagi significava "os que trabalham" e se referia àqueles que, em oposição ao “'homem eyiguayegui', o homem com lança, guerreiro e caçador”, eram conhecidos como homens "sem lança, o servo; a esses nibotagi, homens e mulheres, correspondia todo o trabalho". Ou seja, os niniotagi eram definidos por não fazerem as atividades das quais se ocupavam os nibotagi, pois, como já escreveu Susnik (ibidem, tradução minha), “certos trabalhos por si mesmos indicavam logo o status de nibotagi; por essa razão, todos os comuns possuíam dois ou mais 'nibotagi', para não cair na vergonha social do trabalho".

Ainda que estivesse se referindo à suposta ignomínia a que os niniotagi seriam submetidos pela realização de atividades consideradas por ela "inferiores”, Susnik parece ter acertado ao usar o termo “vergonha”. Muito encontrada na literatura sobre os Jê, a noção de "vergonha” se refere, naquele contexto, à observância de certos protocolos de comportamento que acabam por introduzir e manter distâncias entre recém-casados, sogros e genros e amigos formais, mas não só: segundo Coelho de Souza (2004: 30), a pertinência da "vergonha" ultrapassa largamente o campo das relações entre afins. Entre os Krahô, por exemplo, "denota timidez, reserva, autocontrole, observância da etiqueta, distância social, desempenho de papéis sociais" em diversos níveis (Carneiro da Cunha, 1978:123). Ainda que essa não tenha sido a intenção de Susnik, sugiro ser possível ler a "vergonha" dos nobres eyiguayegui em uma chave parecida com aquela dos grupos jê, podendo ser entendida como um acatamento a certas normas de comportamento que marcam distinções entre estatutos diversos, recorrentemente construídos pela observação cotidiana desses protocolos (ver, por exemplo: Melatti, 1979; Seeger, 1981; Coelho de Souza, 2004).

Como afirmei acima, a "aristocracia" eyiguayegui parecia se distinguir por seu "porte específico, comedimento e boa educação". Todas essas características, por sua vez, parecem constituir essa "vergonha” ameríndia, que parece ser, não apenas entre os Eyiguayegui, o maior distintivo de classes mais "prestigiosas"; entre os Ramkokamekra, por exemplo, existem grupos de pessoas que são mais suscetíveis à "vergonha”: segundo Coelho de Souza (2004: 31), os indivíduos da classe dos hamren, constituído por pessoas que ocupam certas posições de prestígio, têm muito pahâm (vergonha) em relação a outras classes. Uma comparação entre as divisões de tarefas eyiguayegui e os escritos sobre o decoro entre vários grupos jê poderia indicar vários caminhos de análise, o que demandaria um esforço que não pode ser feito aqui. Sugiro apenas que se entendermos a "vergonha" dos niniotagi em se ocupar com determinadas tarefas não como um descrédito às atribuições dos nibotagi, mas como um respeito a certos protocolos de comportamento que constroem e mantêm determinadas distâncias, veremos como os diferentes estatutos e, portanto, diferentes pessoas, estavam sendo construídas de acordo com suas atribuições, ou melhor, se construíam na adoção do comportamento condizente com sua posição. 
É possível encontrar um sentimento parecido, também vinculado a certas distâncias institucionalizadas, nas relações entre anfitriões e convidados nos arete guasu, grandes festas de convite realizadas pelos mburuvicha (chefes) chiriguano e chané (povos que constituem o outro caso conhecido de "hierarquia" no Chaco). Segundo Domínguez (2020), aqueles que faziam o convite e ofereciam a festa demonstravam seu prestígio e influência, enquanto os chefes convidados demonstravam sua "vergonha" e eram impelidos a dar festas ainda maiores, em uma disputa pelo prestígio (ver: Nino, 1912).

A oposição niniotagi/nibotagi não era a única a ser construída por este decoro ou código de honra: as relações entre homens e mulheres também pareciam seguir estes protocolos, que foram interpretados pelos autores das fontes históricas de maneira parecida com a oposição entre "senhores" e “escravos". Se, de um lado, os homens eram recorrentemente colocados pelas fontes no âmbito público e político, as mulheres eram descritas no domínio do particular e do doméstico, caso nada raro nas descrições e análises americanistas, que repetem tais correlações como se nelas houvesse algo de universal, transcultural ou natural. Vejamos as tarefas consideradas femininas.

\section{Escravidão como essência feminina: as atribuições das mulheres nobres e não nobres}

As mulheres cativas, quando não são descritas como "concubinas" de seus donos, são retratadas realizando as mesmas atividades dos cativos homens. As mulheres "nobres", por sua vez, são descritas em uma clara oposição aos "senhores": de acordo com as fontes, ao mesmo tempo em que ambos compartilhavam o "sangue nobre", suas tarefas eram diametralmente opostas. Em contraposição a seus maridos, pais e irmãos - ocupados, do ponto de vista dos europeus que aportaram no Chaco, com atividades políticas como a guerra e as reuniões de caciques - as "donas" pareciam se reduzir ao espaço doméstico: elas cozinhavam, teciam casacos, camisas, ponchos de lã das ovelhas, colhiam cocos, feijões, frutas e raízes, faziam as esteiras, as louças, potes e panelas. Acima de tudo, elas são descritas fazendo as pinturas corporais e tirando todos os pelos - sobrancelhas e pestanas - dos próprios rostos e dos seus maridos, filha/os e cativa/os, em um processo que parecia levar longas horas. A distinção entre as atribuições da nobreza feminina e masculina culminou em uma oposição que subsiste até hoje nas análises antropológicas e historiográficas: aquela entra a arte e a guerra ${ }^{10}$.

Essa "divisão sexual do trabalho" descrita pelas fontes e pela literatura atual não traz nenhuma grande novidade para a etnologia. Ela é geralmente considerada a primeira e mais simples forma de organização social, à qual vem se sobrepor outros tipos de diferenciação, como as distinções "rituais", de classe, etc. Mas é importante notar que, no caso dos Eyiguayegui, praticamente todas as atividades consideradas femininas são compartilhadas pelos nibotagi: ambos cozinhavam, carregavam os pertences nas mudanças de tolderías e "acompanhavam" as expedições guerreiras, por exemplo. As fontes muitas vezes nos confundem ao descrever as atividades dos "escravos" ou das mulheres nobres, e a sensação é a de que os próprios autores se atrapalham na categorização dessas atribuições.

10 A oposição entre arte e guerra é discutida mais a fundo em Freire (2018). 
É interessante salientar que essa relação entre feminilidade e escravidão não é exclusiva dos escritos sobre os Eyiguayegui: a antropóloga Beatriz Vitar (2001: 239, tradução minha), por exemplo, fala da criação, pelas fontes jesuíticas, de uma "imagem subordinada e servil" das mulheres indígenas chaquenhas. Segundo o missionário Pedro Lozano (1873: 76) citado pela autora, por exemplo, as mulheres guaicurú seriam "como escravas perpétuas de seus maridos", ainda que levassem com eles uma vida conjugal.

Além disso, de maneira similar àquela dos nibotagi, as tarefas da maioria das mulheres também são retratadas como "árduas". Observando a distribuição das tarefas nas tolderías eyiguayegui, por exemplo, Émile Rivasseau ([1936]:72) escreve que "em todas as tribos indianas" é normal que se atribua às mulheres "os trabalhos mais duros e mais penosos", julgando normal que, nessas circunstâncias, elas sejam consideradas "ainda mais ou menos como escrava[s]". Essa sobreposição da distinção entre "nobres" e "escravos" à divisão sexual do trabalho parece ser consenso nas fontes analisadas. E não apenas às fontes: Fernando Santos-Granero chega a afirmar, sobre os trabalhos realizados pelos "escravos" ameríndios, que os "cativos homens eram frequentemente obrigados a executar tarefas menores, que eram consideradas dominio das mulheres" (Santos-Granero, 2009:128, tradução e grifos meus), o que seria prova do controle de seus capitães sobre eles.

E não apenas a divisão sexual das tarefas é uma velha conhecida da Antropologia: mesmo as funções definidas como masculinas e femininas são apresentadas como universais - de um lado os homens caçam e guerreiam e, de outro, as mulheres cozinham, cuidam das crianças, tecem, fazem cerâmica... É possível fazer um paralelo entre as narrativas dos cronistas e as descrições dos Aché-Guayaki de Pierre Clastres, no qual existe, segundo o autor, "um espaço masculino e um espaço feminino, respectivamente definidos pela floresta onde os homens caçam e pelo acampamento onde reinam as mulheres" (2003:122). Ali, tarefas de homens e mulheres definiriam a própria existência masculina - "que só se torna autêntica quando realizada" na caça - e feminina - definida pelas funções da maternidade e do casamento $^{11}$. De maneira parecida, os autores dos documentos históricos definem homens e mulheres, nibotagi e niniotagi. Em seus escritos há uma relação direta entre o que as pessoas fazem e o que elas são: aos homens nobres, o movimento e a floresta; às mulheres e "escravos", o sedentarismo e as tolderías. Assim, uma divisão de tarefas que poderia ter origem em um decoro e em normas não fixas de comportamento passou a ser lida pelos relatos como diferenças inatas a homens, mulheres, nobres e "escravos", que acabariam por distingui-los hierarquicamente.

Por isso, quando uma mulher ia para guerra, um nobre cozinhava e um nibotagi caçava, por exemplo, os autores das fontes tendiam a considerá-los como desvios à regra. É o caso dos cudina que, segundo Almeida Serra (1850:358), eram homens que faziam os "mesmos trabalhos" que as mulheres. Ele(a)s eram descrito(a)s como "homens que affecta[va]m todos os modos das mulheres; vest[ia]m-se como ellas, ocupa[va]m-se em fiar, tecer, fazer panelas, etc.", vistos como verdadeiras aberrações, "ne-

11 Esse paralelo entre os dados trazidos por P. Clastres sobre os Aché-Guayaki e aqueles trazidos pelas fontes sobre os Eyiguayegui é mais desenvolvido em Freire (2018). A ideia de que as mulheres seriam "naturalmente" compelidas ao ambiente doméstico e à procriação que é afirmada pelas fontes é também trazida por Pierre Clastres, que a questiona posteriormente em outro ensaio, "O infortúnio do guerreiro selvagem" (2004). A solução clastreana para o problema das mulheres eyiguayegui que seriam, assim como os homens, seres-para-a-morte, é também discutida por mim na dissertação. 
fandos demônios”. O fato de esses homens terem assumido - assim como Krembegi, indígena guayaki apresentado por Pierre Clastres (2003: 127) - "até as últimas consequências sua condição de home[ns] não-caçador[es]", abandonando o arco para viverem "como mulheres", era para as fontes inconcebível.

O exemplo da reação violenta dos cronistas à existência dos cudinas revela a necessidade desses autores de atribuir lugares fixos aos personagens de seus relatos. Sua tentativa de impor às populações chaquenhas formas de relação com características marcadamente europeias acabava por fazê-los procurar categorias intermediárias quando homens não cumpriam o que eles entendiam como seu destino natural - a caça e a guerra - e quando os nibotagi começavam a se destacar por seus feitos guerreiros, passando a ocupar posições de chefia. Cativos que se tornavam guerreiros, por exemplo, parecem ser entendidos pelas fontes como pessoas em um estado de transição da "escravidão" para a "nobreza", sendo alocados na camada dos "comuns", assim como os cudinas eram entendidos como homens que estavam em seu caminho de ser tornarem mulheres.

Aliás, é interessante perceber o paralelo possível entre os cudinas eyiguayegui e os two-spirit norte-americanos (por muito tempo conhecidos como berdache), aquelas pessoas que foram muitas vezes denominadas como "travestis" ou "homossexuais". Nos dois casos, as fontes históricas localizam a transformação destes "homens" em "mulheres" no momento em que ele(a)s passam a realizar tarefas consideradas femininas. "Entre os Yurok, por exemplo, um homem jovem se torna wergern [two-spirit] quando começa a tecer cestas" e, depois deste momento, ele logo passa a "se vestir como mulher" (Désy, 1993:19). Também entre os Pima, "um menino que mostra uma predileção por brincar com cestas será 'como uma menina"' (ibidem). A suposta capacidade de transformação de gênero contida nessas atribuições, porém, não será discutida no presente trabalho. O importante aqui é salientar que essas tarefas não apenas não são fixas a homens e mulheres, "escravos" e "senhores", como também parecem ter a capacidade de operar transformações corporais e de afetar as distinções que operam entre os Eyiguayegui.

\section{Considerações finais: as atribuições como matéria do devir}

Parece haver uma multiplicidade de pontos de vista que se atravessam e são expressados pelas fontes. O que seus dados permitem entrever é que havia mesmo algo como um "código de honra" (ou decoro) que demarcava contextualmente certas distâncias; essas distâncias, por sua vez, pareciam se exprimir também nas diferentes tarefas realizadas pelas pessoas. Ou seja, niniotagi e nibotagi, homens e mulheres eram realmente distintos por suas atividades, mas não de uma maneira estanque e imutável, e é por isso que as fontes narram movimentos de transição (ou transformação) entre um estatuto e outro. Não sendo algo "natural" ou imutável, e podendo ser produzidos e reafirmados por meio do comportamento, esses estatutos não eram estanques, ou matéria do ser, e sim transformacionais, questão do devir, da transição entre um modo de existência e outro. A leitura dos registros históricos nos leva a acreditar que, quando uma pessoa passava a se ocupar de atribuições típicas de outros estatutos, seu corpo mudava e, com ele, sua posição em relação às outras pessoas. Mudam-se as atribuições, muda-se também a posição ocupada na rede de relações dos nibotagi, niyolola, elegi, homens, mulheres e cudinas. 
Os cronistas, viajantes e missionários autores das fontes, porém, acabaram por interpretar as diferentes atribuições não apenas como distintas - como elas pareciam ser lidas pelos indígenas - mas também como desiguais em valor, definindo as categorias que povoavam as tolderías eyiguayegui por meio do "trabalho" executado pelas pessoas e afirmando serem algumas delas inferiores e outras superiores. Mas a análise atenta desses documentos mostra que em nenhum momento os Eyiguayegui diziam não realizar tais tarefas por serem elas inferiores a seu status. Se por um lado os dados trazidos por essas fontes permitem ver que as tarefas eram diferentes entre pessoas distintas, por outro, eles colocam em dúvida o fato de que essa diferença era concebida em termos de superioridade e inferioridade.

Nesse sentido, é necessário atualizar esse debate sobre as atribuições entre os Kadiwéu. É preciso realizar mais pesquisas que tenham como objetivo entender de que modo essas atribuições operam transformações nos corpos e nos estatutos eyiguayegui e kadiwéu. Se os "senhores" continuam a delegar certas atividades a outras pessoas, é imprescindível entender qual é o sentido conferido a essas atribuições por quem as rejeita e por quem as realiza de fato. É necessário também aliar às descrições que tomam a perspectiva eyiguayegui como central aquelas produções que focam no que os "servos" e "escravos" pensam dessas relações (ver, por exemplo, Cordeu, 2004). Talvez assim, por meio do diálogo com "senhores" e "servos" a Etnologia dos Kadiwéu possa começar a entender o princípio das distinções entre esses estatutos.

\section{Gabriela de Carvalho Freire émestra em Antropologia Socialpela Universidade de São Paulo (USP) e doutoranda na mesma instituição. É antropóloga respon- sável pela Seção de Etnologia Indígena do Museu de Arqueologia e Etnologia da Universidade Federal do Paraná (MAE-UFPR). A pesquisa que fundamentou $o$ artigo obteve financiamento da Capes.}

\section{REFERÊNCIAS}

\section{Fontes históricas}

Aguirre, D. J. F. ([1793] 1898). Etnografía del Chaco. Manuscrito del Capitán de Fragata D. Juan Francisco Aguirre. Boletin del Instituto Geográfico Argentino, tomo XIX. Buenos Aires, Local del Instituto.

Almeida Serra, R. F. (1844). Extracto da Descripção da Provincia de Mato-Grosso, feita em 1797, feita por Ricardo Franco de Almeida Serra, Sargento-Mór de Engenheiros. Revista do Instituto Histórico e Geográfico do Brasil, 6, 156 - 196. 
Almeida Serra, R. F. (1845). Parecer sobre o aldeamento dos índios Uiacurús e Guanás com a descripção dos seus usos, religião, estabilidade e costume. Revista do Instituto Histórico e Geográfico Brasileiro, 7, 196-208.

Almeida Serra, R. F. (1850). Continuação do parecer sobre os índios Uaicurús e Guanás. Revista do Instituto Histórico e Geográfico Brasileiro, 13, 348-395.

Azara, F. ([1809] 1923). Viajes por la América Meridional, v. I. Madrid: Calpe.

Boggiani, G. ([1895] 1975). Os caduveos. Belo Horizonte, Editora Itatiaia.

Cabeza de Vaca, A. N. ([1555] 1987). Naufrágios e Comentários. Porto Alegre: L\&PM Editores.

Caceres, L.A.M. (1865). Exploração do Rio Paraguay e Primeiras Práticas com os índios Guaikurús Revista Trimensal do Instituto Histórico Geográfico e Ethnographico do Brasil, tomo XXVIII (p. 70117).

Castelnau, F. ([1850] 1949). Expedição às Regiões Centrais da América do Sul. São Paulo: Coleção Brasiliana.

Debret, J B. (1834-1839). Voyage pittoresque et historique au Brésil: séjour d'um artiste français au Brésil, depuis 1816 jusqu’en 1831. Paris: Firmin Didot.

Debret, J. B. ([1834] 1972). Viagem pitoresca e histórica ao Brasil. São Paulo: EDUSP, 2 v.

Dobrizhoffer, M. ([1784] 1970). Historia de los Abipones. Santa Fe: Universidad Nacional del Litoral. Lozano, P. (1873). Historia de la conquista del Paraguay, Rio de la Plata y Tucuman. Buenos Aires: Casa Editora Imprenta Popular.

Paucke, F. ([1743-1767] 1942-1944). Hacia allá y para acá. Una estada entre los mocovies. Tucumán/ Buenos Aires: Universidad Nacional de Tucumán/Institución Cultural Argentino-Germana.

Rengger, J. R. (2010). Viaje al Paraguay en los años 1818 a 1826. Assunção: Tiempo de Historia, Rivasseau, E. ([1936] 1941). A vida dos Indios Guaycurús: Quinze dias nas suas aldeias. São Paulo: Companhia Editora Nacional.

Rodrigues do Prado, F. (1795). História dos Índios Cavalleiros ou da Nação Guaycurú. Revista do Instituto Histórico e Geográfico Brasileiro, I: 25-57.

Sánchez-Labrador, J. ([1770-1776] 1910). El Paraguay Católico. Buenos Aires: [s.i.], 2 v.

Schmidel, U. ([1602] 1986). Relatos de la conquista del Rio de la Plata y Paraguay 1534-1554. Madrid: Alianza Editorial. 
Taunay, A.E. (1931). Entre os nossos indios: entre Chanés, Terenas, Kinikinaus, Guanás, Laianas, Guatós, Guaycurús, Caingangs. São Paulo: Editora Melhoramentos.

Taunay, A.E. (1874). De Ierecê a Guaná. In: S. Dinarte (org.). Histórias Brazileiras (pp. 11-62). Rio de Janeiro.

\section{Bibliografia}

Carneiro da Cunha, M. (1978). Os mortos e os outros. Uma análise do sistema funerário e da noção de pessoa entre os indios Krahó. São Paulo: Hucitec.

Clastres, P. (1974). La société contre l'État: Recherches d'anthropologie politique. Paris: Éditions de Minuit.

Clastres, P. ([1974] 2003). A sociedade contra o Estado: pesquisas de antropologia politica. São Paulo: Cosac Naify.

Clastres, P. ([1980] 2004). Arqueologia da Violência: pesquisas de antropologia política. São Paulo: Cosac Naify.

Coelho de Souza, M. (2004). Parentes de Sangue: incesto, substância e relação no pensamento Timbira. Mana, 10 (1), 25-60. https://doi.org/10.1590/S0104-93132004000100002

Combès, I, Lowrey, K., \& Villar, D. (2009). Comparative studies and the South American Gran Chaco. Tipití, 7(1), Article 3. Disponível em https://digitalcommons.trinity.edu/tipiti/vol7/iss 1/3/

Cordeu, E. J. (2004). Los Tomaraxo del Chaco Boreal y los "indios caballeros" (caduveo). Aportes para la etnohistoria de un sistema intertribal. In: M. S. Cipoletti (org.) Los mundos de abajo y los mundos de arriba. Individuo y sociedad en las tierras bajas, en los Andes y más allá (pp. 276-312). Quito: Abya-Yala.

Désy, P. (1993). The Berdaches: "Man-Woman in North-America". Classiques des Sciences Sociales - UQAC. Disponível em http://classiques.uqac.ca/contemporains/desy_pierrette/the_berdaches/ desy_the_berdaches_pp.pdf

Domínguez, M. E. (2020). Um lugar onde se achar. Deslocamentos e rituais entre os Guarani do Chaco boreal paraguaio. Revista de Antropologia, 63(2), e157328. https://www.revistas.usp.br/ra/ article/view/157328/167895

Duran, M. R. C. (2016). Leituras antropológicas sobre a arte kadiwéu. Cadernos de Campo, 24(24), 43-70. https://doi.org/10.11606/issn.2316-9133.v24i24p43-70

Freire, G. C. (2018). Distinçôes eyiguayegui (Dissertação de Mestrado). Universidade de São Paulo, São Paulo. 
Guerreiro Jr., A. (2012). Ancestrais e suas sombras: uma etnografia da chefia kalapalo e seu ritual mortuário (Tese de Doutorado). Universidade de Brasília, Brasília.

Herberts, A. L. (2011). Panorama histórico dos Mbayá-Guaikuru entre os séculos XVI e XIX. In: G. José da Silva (org) Kadiwéu: Senhoras da arte, senhores da guerra (pp. 17-47). Curitiba: Editora CRV.

José da Silva, G. (2004). A construção física, social e simbólica da Reserva Indígena Kadiwéu: memória, identidade e história (Dissertação de Mestrado). Universidade de Mato Grosso do Sul, Dourados.

José da Silva, G. (2011). A reserva indígena Kadiwéu (1899-1994): demarcação e conflitos pela pesse de terra. In: José da Silva, G. (org) Kadiwéu: Senhoras da arte, senhores da guerra (pp. 50-72). Curitiba: Editora CRV.

José da Silva, G., \& Kok, M (org.). (2014). Kadiwéu: Senhoras da arte, senhores da guerra v. II. Curitiba: Editora CRV.

Lecznieski, L. (2005). Estranhos laços: predação e cuidado entre os Kadiwéu (Tese de Doutorado). Universidade Federal de Santa Catarina, Florianópolis.

Lévi-Strauss, C. ([1955] 1996). "Parte V - Cadiueu” "Nalike”. In: Tristes Trópicos (pp. 163-210). São Paulo: Companhia das Letras.

Lowie, R. (1948). Social and Political Organization of the Tropical Forest and Marginal Tribes. In: J. Steward (ed.). Handbook of South American Indians, v. 5 (pp. 313-350). Washington D.C.: Government Printing Office.

Melatti, J. C. (1979). The relationship system of the Krahó. In: D. Maybury-Lewis (ed.), Dialectical Societies: The Ge and Bororo of Central Brazil (pp. 46-79). Cambridge: Harvard University Press.

Métraux, A. (1946). Ethnography of the Chaco. In: J. Steward (ed.). Handbook of South American Indians: The Marginal Tribes, v. I (pp. 197-370). New York, Cooper Square Publishers.

Nino, B. (1912). Etnografia chiriguana. La Paz: tipografia comercial I. Argote.

Padilha, S. (1996). A arte como trama do mundo: corpo, grafismo e cerâmica Kadiwéu (Dissertação de Mestrado). Universidade de Brasília, Brasília.

Pechincha, M. (1994). Histórias de admirar: mito, rito e história kadiwéu (Dissertação de Mestrado). Universidade de Brasília, Brasília.

Perrone-Moisés, B. (2015). Festa e Guerra (Tese de Livre-Docência). Universidade de São Paulo, São Paulo.

Perrone-Moisés, B. \& Lolli, P. (2017). A ilusão hierárquica nas Américas. Ms. 
Radin, P. (1946). Indians of South America. New York: Doubleday \& Company, Inc.

Ribeiro, D. (1980a). Kadiwéu: ensaios etnológicos sobre o saber, o azar e a beleza. Rio de Janeiro: Petrópolis.

Ribeiro, D. (1980b). Sistema familial kadiwéu. In: Uirá sai à procura de Deus: ensaios de etnologia e indigenismo (pp. 175-192). Rio de Janeiro: Paz e Terra.

Santos-Granero, F. (2009). Vital enemies: slavery, predation and the Amerindian Economy of Life. Austin: University of Texas Press.

Santos-Granero, F. (2016). Masters, slaves and real people: native understandings of ownership and humaneness in Tropical American Capturing Societies. In: M. Brightman, C. Fausto \& V. Grotti (ed.) Ownership and nurture: studies in native Amazonian property relations. New York: Oxford, Berghan Books.

Seeger, A. 1981. Nature and society in central Brazil: The Suya Indians of Mato Grosso. Cambridge: Harvard University Press.

Siqueira Jr, J. (1992). Arte e técnica kadiwéu. São Paulo: Secretaria de Cultura.

Siqueira Jr, J. (1992b). A iconografia kadiwéu atual. In: L. Vidal (org.). Grafismo indígena: estudos de antropologia estética (pp. 265-277). São Paulo: Edusp.

Siqueira Jr, J. (1993). Essa terra custou o sangue de nossos avós: a construção do tempo e espaço Kadiwéu Paulo (Dissertação de Mestrado). Universidade de São Paulo, São Paulo.

Susnik, B. (1972). Dimensiones migratorias y pautas culturales de los pueblos del Gran Chaco y de su periferia (enfoque etnológico). Asunción: Universidad Católica Nuestra Señora de la Asunción.

Tola, F. C. (2013). Introdución. Acortando distancias: El Chaco, la antropologia y la antropologia del Chaco. In: Ontologia, poder, afectividad (pp. 11-37). Buenos Aires: Rumbo Sur, Colección etnográfica.

Villar, D. (2011). RENNGER, Johann Rudolph, Viaje al Paraguay en los años 1818 a 1826. Journal de la Societé des americanistes, 97-2. Disponível em http://journals.openedition.org/jsa/11997.

Villar, D. (2013). Modelos de liderazgo ameríndio. In: Al pie de los Andes. Estudios de etnología, arqueología y historia (pp. 11-31). Cochabamba: Itinerarios Editorial.

Vitar, B. (2001). Las mujeres chaqueñas en las reducciones fronterizas del Tucumán: entre la tradición y el cambio (siglo XVIII). Anuario IEHS: Instituto de Estudios Historicos y Sociales, 16. (pp. 223-244). 
Viveiros de Castro, E. B. (1979). A fabricação do corpo na sociedade xinguana. Boletim do Museu Nacional, Série Antropologia (32), 40-49.

Viveiros de Castro, E. B. (1983). Hierarquia e simbiose em questão. Anuário Antropológico, 81, 252262. https://periodicos.unb.br/index.php/anuarioantropologico/article/view/6200

Viveiros de Castro, E. B. (1996). Os pronomes cosmológicos e o perspectivismo ameríndio. Mana, 2(2), 115-144. https://doi.org/10.1590/S0104-93131996000200005

Viveiros de Castro, E. B. (2002). A inconstância da alma selvagem. São Paulo: Cosac Naify.

Viveiros de Castro, E. B. (2004). Posfácio: O intempestivo, ainda. In: P. Clastres, Arqueologia da violência: pesquisas de antropologia política (pp. 297-361). São Paulo: Cosac Naify. 


\title{
O PAPEl das ATRibuiçốes na CONSTITUiÇão da hierarquia KADIWÉu: UMA ANÁLISE DAS DISTINÇÕES EYIGUAYEGUI
}

Resumo: O artigo revisita os escritos de agentes coloniais acerca dos Eyiguayegui e dos Guaná - de quem os atuais Kadiwéu e Terena se autodenominam descendentes - e de sua suposta hierarquia. Por meio da leitura dessas fontes em conjunto com reflexões antropológicas contemporâneas sobre os Kadiwéu, populações do Chaco e outros povos ameríndios, pretendo apresentar o papel das diferentes atribuições na construção das distinções entre aqueles que as fontes denominam "senhores", "escravos" e "servos", e até mesmo entre homens e mulheres. Noções de trabalho e de âmbitos público e doméstico são mobilizados na discussão, que reflete acerca das assimetrias e das relações de gênero principalmente entre os Eyiguayegui e Kadiwéu.

Palavras-chave: Gran Chaco; Kadiwéu; Terena; Assimetrias; Formas políticas ameríndias.

\section{THE ROLE OF ATTRIBUTION IN THE CONSTITUTION OF THE KADIWÉU HIERARCHY: AN ANÁLISIS OF EYIGUAYEGUI DISTINCTIONS}

\begin{abstract}
This article revisits the writings of colonial agentes about the Eyiguayegui and the Guaná - from whom the current Kadiwéu and Terena call themselves descendants - and their supposed hierarchy. By reading these sources in conjunction with contemporary anthropological reflections on the Kadiwéu, the populations of the Chaco and other Amerindian peoples, I intend to present the role of different attributions in the construction of the distinctions between those whom the sources call "masters", "slaves" and "servants", and even between men and women. Notions of work and of the public and domestic spheres are mobilized in the discussion, which reflects on the asymmetries and gender relations, manly among the Eyiguayegui and Kadiwéu.
\end{abstract}

Keywords: Gran Chaco; Kadiwéu; Terena; Assymmetries; Amerindian political forms.

RECEBIDO: $04 / 07 / 2020$

APROVADO: $07 / 04 / 2021$ 